\begin{abstract}
Given the increasing use of online platforms, the current research comprised two studies examining links between personality and emoticon use: Study 1 explored the psychological factors associated with emoticon usage on different online platforms $(N=92)$, and Study 2 assessed the accuracy of a group of observers' personality judgements of Facebook users $(N=$ 54). Participants in Study 1 comprised previously unacquainted dyads who each completed measures on their Big-5 personality, self-esteem, social anxiety, self-presentation, and selfreported usage of emoticons on email, text messages and Facebook. Participants provided Facebook data and interacted online with each other for ten-minutes. Trait analysis revealed that agreeableness was positively related to self-reported emoticon usage on Facebook, but not in texts or emails. In Study 2, observers viewed the Facebook stimuli and made personality assessments of the dyad members. Judgement accuracy was determined by correlating these assessments with targets' own self-reported personality. Analyses revealed the highest level of accuracy for extraversion and openness. Finally, positive correlations were found between objective usage of "happy" emoticons and observers' assessments of targets' agreeableness, conscientiousness and openness. Taken together, findings indicate the importance of specific online behaviours in self-presentation, and their impact on judgement accuracy.
\end{abstract}

Keywords: Self-presentation; online; personality; first impressions; emoticons 
EMOTICON USAGE AND PERSONALITY JUDGEMENTS

\section{An exploration of psychological factors on emoticon usage and implications for judgement accuracy}

\section{Introduction}

Online interaction is important in daily life and can be used to transmit, and receive, information to others via a range of digital platforms (e.g., health forums; Alfi \& Talbot, 2013). Importantly, online interaction often goes beyond these functions, resulting in increasing research attention to the opportunities that online interaction permits in terms of presenting a particular sense of 'self', typically known as Self Presentation (SP: Goffman, 1990; Schlenker, 2003). Given the rise and popularity of virtual platforms, SP in an online context is a key concern in contemporary society. Social networking sites (SNSs) are of particular interest due to the range of opportunities available for users to select the way they present themselves to others and upload personal information. Although initial investigation has examined whether people engage in SP online (Bullingham \& Vasconcelos, 2013), the individual differences related to SP and online behaviour across contexts has not been fully established.

The identification of key correlates of online behaviour is of interest as it can help elucidate the underlying reasons for the users' behaviours. The present study investigates this issue across different online platforms to gain a richer understanding of user-context interactions. Critically, one of the reasons that people engage in SP is to make an impression on another person (Leary, 1995), therefore, it would seem important to examine how individual and contextual differences in online behaviour affect the first impressions that other people form about us. In addition to being practically important, an investigation into the impact that online behaviour has on first impressions can develop our theoretical understanding of how people form first impressions online. Accordingly, Study 1 explores the psychological correlates of online behaviour, in the form of emoticon usage, therefore focusing on the user's perspective; 
and Study 2 examines the impact of online behaviour on the validity, or 'accuracy', of first impressions, thus focusing on an observer's perspective. The importance of this multiperspective approach relates to previous commentary highlighting individual differences in the types of behavioural cues people use on SNS (e.g., Mehdizadeh, 2010), and how this in turn, impacts upon others' first impressions of users (Burke, 2004; Wall, Taylor, Conchie, Dixon, \& Ellis, 2013).

\subsection{Self-presentation and individual differences in online behaviour and implications for first impression accuracy}

Individuals vary in the extent to which they monitor their behaviour (self-monitoring, Snyder, 1987). Those who are high in SP tend to alter their behaviour to present themselves in a favourable light, while those low in SP tend to present themselves in the same manner regardless of the context (Leary \& Allen, 2011). As many interactions between individuals are now initiated online (e.g., online dating and Skype interviews for job recruitment: Rosenfield, 2010), understanding the psychological factors underpinning users' online SP behaviour and its subsequent impact on others' judgements presents a pertinent concern. Within the online context, levels of SP and associated behavioural monitoring are likely to be associated with

variations in online behaviours. Indeed, previous research has highlighted the utility of Goffman's (1990) early work on SP within the context of online environments (Bullingham \& Vasconcelos, 2013). However, less is understood about other psychological correlates of online SP efforts (cf. Ong, Ang, Ho, Lim, Goh, Lee, \& Chua, 2011; Mehdizadeh, 2010) and therefore the psychological processes underlying why people behave as they do online remains open to question and is examined in Study 1. Importantly, given the anonymity in many forms of online interactions (Misoch, 2015) and enhanced likelihood of socially desirable responding when assessing a construct like SP it would seem imperative to examine actual online behaviours 
(see Vohs, Baumeister, \& Funder, 2007). Critically, this study represents the first attempt to examine psychological and contextual differences in online behaviour and first impressions using a combination of self-report and behavioural coding to measuring a specific type of online behaviour - emoticon usage.

'Emoticons' may serve as a useful behaviour through which to examine the relationship between SP and individual differences across contexts. These text-based symbols provide an online equivalent of facial expressions in face-to-face interactions, allowing users to communicate their intended emotions (Derks, Bos \& Grumbkow, 2008). The use of emoticons helps to circumvent the ambiguity associated with some forms on online communication (Kruger, Epley, Parker, \& Ng, 2005), by supporting the reader to decipher intent in ambiguous messages (Ganster, Eimler, \& Kramer, 2012; Kaye, Wall \& Malone, in press). They also ease communication by providing information to the recipient that assists in regulating the interaction and expressing intimacy. Thus, it is possible that people's use of emoticons may represent attempts to control their own behaviour and it is interesting to examine the use of this specific type of online behaviour across contexts.

When considering what elements of online contexts may be useful in advancing our understanding of SP and the psychological correlates underlying emoticon usage the publicprivate dimension represents a useful distinction. There are a range of online platforms that vary in terms of the private (e.g., email) versus more public (e.g., Facebook, websites) nature. Critically, these platforms may also vary in terms of the synchronicity of communication (Facebook) or editing capabilities (website). Given the differences in the public nature of these platforms, it is possible this leads to differences in SP use, as supported by previous research showing such variations resulting from individual differences and different Internet arenas (Attrill, 2012; Fullwood, 2015; Kaye et al., in press). Importantly, the platforms of interest all permit emoticons as a form of expressive behaviour. 


\subsection{Theoretical Frameworks}

Drawing upon Walther's hyperpersonal model of Computer Mediated Communication (CMC: 1993, 1996), it is possible that emoticon usage enables individuals to adapt their linguistic and textual behaviour to overcome non-verbal limitations in CMC, thus aiding impression development. Although substantive, this theory does not necessarily offer a full explanation for the way in which individuals may disclose information differently across online contexts (Attrill, 2012) nor does it provide compelling evidence of the way in which variations between individuals affects specific online behavioural communication. The present focus on contextual differences in emoticon usage and how this relates to key psychological variables aims to develop and extend this line of theorising.

The importance of context and person on behaviour has been acknowledged in the interpersonal perception literature (Lextzring, Wells, \& Funder, 2006; Wall, Taylor, \& Campbell, 2016). Specifically, studies examining theoretical models of the accuracy process (Funder, 1995, 1999) have identified four key moderator variables. These are the information on which a judgement is based (i.e., context), the specific trait being judged, the target person being judged and the characteristics of the person making the judgment (i.e., the observer). The notion that context and type of information relates to trait-specific accuracy (Gosling, Augustine, Vazire, Holtzman, \& Gaddis, 2011) highlights a useful avenue for the present focus on first impression accuracy in SNS. Indeed, evidence has revealed observers' personality judgements of users based on Facebook profiles, to be highly convergent with users' actual personality assessments when rating certain traits (Back et al. 2010; Gosling, Gaddis \& Vazire, 2007). This suggests that we reveal aspects of our personalities online that observers can readily detect. An exploration into users' online behaviours across online contexts and associated first impression accuracy can increase our understanding of how accurate judgements are formed. 
Before examining first impression accuracy across platforms based on emoticon cue usage, the first step is to explore individual differences in emoticon usage and SP across platforms. This examination represents the aim of Study 1.

\section{Study 1: Psychological Factors and Emoticon Usage across Platforms}

There are a number of key psychological factors that are conceivably related to emoticon usage in online contexts. In particular, as well as acknowledging SP as an important factor, the current research focused on the factors of personality, social anxiety and self-esteem. These will be discussed in the subsequent sections.

Previous evidence points to the role of personality as a relevant factor in determining online behaviours (Amichai-Hamburger \& Vinitzky, 2010; Eftekhar, Fullwood, \& Morris, 2014; Fullwood, 2015). In particular, specific personality traits have been found to be associated with levels of SP and self-promotion on social networking sites (Carpenter, 2012; Marriot \& Buchanan, 2014; Rosenberg \& Egbert, 2011). For example, individuals high in the trait of agreeableness tend to be more concerned with SP, presumably as they often have greater concerns about being cooperative and friendly (Leary \& Allen, 2011). Similarly, Gosling et al. (2011) explored relations between traits and online behaviours such as posting of photos and social engagement (see also Walther, Van de Heide, Kim, Westeman \& Tong, 2008). Interestingly, a study by Ebeling-Witte, Frank, and Llester (2007) revealed that shyness was associated with problematic internet usage. Taken together, these findings suggest that who we are shapes what we do in online platforms in a number of interesting ways.

A further psychological factor that is conceivably related to online behaviour is social anxiety. Social anxiety is related to SP (Schlenker \& Leary, 1982), in that people with social anxiety are often concerned about the impressions that others form of them (Leary, Kowalski, \& Campbell, 1988). Indeed, other evidence highlights that those high in social anxiety are 
likely to engage in SP tactics to restore a damaged impression (Lee, Quigley, Nesler, Corbett, \& Tedeschi, 1999). Similarly, other research has identified high levels of negative emotionality to be related to SP efforts (Sadler, Hunger, \& Miller, 2010). In relation to forms of social anxiety, these generally relate to two factors: concerns about typical events (e.g., speaking in front of a group or meeting someone for the first time) and about social failures (e.g., being misunderstood). However, these anxiety concerns may operate differently within online interaction contexts. For example, socially anxious individuals may use more emoticons and/or a larger range of emoticons to avoid being judged negatively. In support, previous research has found those high in social anxiety generally have a preference for, and respond differently, in online communication compared to face-to-face interactions (Caplan, 2007; Pierce, 2009; Rauch, Strobel, Bella, Odachowski, \& Bloom, 2014) due to a perception of increased communicative success and control during an online interaction compared to face-to-face interaction (Shalon, Israelo, Markovitzky, \& Lipsitz, 2015). While this provides us with an initial understanding, to date much research has focused on self-reports of online behaviour. The current study uses the innovative approach of utilising both self-report and direct observation of emoticon usage to further our understanding.

The construct of self-esteem represents another key factor that might relate to SP and online contextual differences in emoticon usage. Self-esteem refers to the positive and negative evaluations that individuals attribute to themselves (Coppersmith, 1967) and has been proposed as a proxy measure of how accepted we are by others (Rosenberg, 1965). Those with high selfesteem believe themselves to be more accepted by those around them compared to those lower in this characteristic (Leary \& Baumeister, 2000). Evidence has revealed that self-esteem is a determinant of the nature of self-enhancement behaviours; specifically that those higher in this characteristic use compensatory self-enhancement strategies under conditions which threaten their reputation relative to those lower in self-esteem (Baumeister, 1982). In relation to online 
behaviour, a similar notion has been noted whereby those with higher self-esteem may be likely to sustain their positive self-regard through effective SP efforts (Fullwood, 2015). Thus, it could be expected that self-esteem will be positively related to emoticon usage, as those high in this characteristic are conceivably more likely to engage in this behaviour to maintain positive SP and self-regard. The primary objective of Study 1 therefore was to investigate the relationship between these psychological characteristics and self-reported emoticon use on different online contexts.

\section{Method}

\subsection{Participants}

Participants $(N=92)$ were first year university psychology students taking part for course credit. Participants were asked to complete an online questionnaire for a study interested in "The relationship between the self and online presentation".

\subsection{Design and Procedure}

The study employed a correlational design to explore the role of SP, social anxiety, self-esteem, personality and platform-type on the outcome variable of emoticon usage. To gain measures of individuals emoticon use, they first provided self-report data using a questionnaire method, followed by tasks that obtained direct behavioural responses.

The procedure commenced with the completion of ethical assurances, followed by completing measures on the psychological factors. These questionnaires were counterbalanced across participants to ensure any potential fatigue effects were not subject to particular questionnaires. Additionally, the final section measured emoticon usage in different online contexts (i.e., average number of emoticons used in text messages, Facebook messages and emails per week) and perceptions of privacy. 
On completion of the self-report measures, participants engaged in two tasks through the platform of Facebook. This enabled behavioural measures of emoticon usage to be obtained. First, participants were asked to $\log$ in to their Facebook account so that the researcher could take static screen shots of their "profile page". Second participants were asked to engage in a 10-minute online 'chat' conversation with an unknown user (another participant taking part concurrently) through an alternative Facebook profile set up for the purposes of the study (i.e., anonymous account purely for the purposes of an instant 'chat' exchange). In line with recent research (see Carney \& Colvin, 2004; Wall et al., 2013) participants were instructed to 'talk about anything they like' to encourage natural conversation and online behaviours.

\subsection{Materials}

3.3.1 Social anxiety. The Liebowitz Social Anxiety Scale (Liebowitz, 1987) was used to measure social anxiety. This 24-item questionnaire examines the extent to which participants feel anxious and avoid tasks in a variety of situations (e.g., using a telephone in public; being the centre of attention). Using a four-point Likert scale, participants indicated their fear $(0=$ none to $3=$ severe $)$ and avoidance of a situation $(0=$ never to $3=$ usually $)$. The current study employed only the social interaction items for anxiety and avoidance which were found to be adequately reliable for both avoidance $(\alpha=88)$ and anxiety associated with social interaction $(\alpha=90)$, consistent with previous research (Heimberg, Horner, Juster, Safren, Brown, Schneier, \& Liebowitz, 1999).

3.3.2 Self-esteem. This was assessed using Rosenberg's Self-Esteem Scale (Rosenberg, 1965). Participants endorsed their agreement with the 10 -items using a Likert scale $(1=$ strongly disagree to 4 = strongly agree). Example items include; "I am able to do things as well as most other people". Previous research has found this measure to be valid (Hagborg, 2006), 
and reliable as determined by internal consistency and test-retest (Fleming \& Courtney, 1984). This was supported by the reliability analysis of the current study $(\alpha=.90)$.

3.3.3 Personality. Personality was assessed using the 50-item International Personality Item Pool (IPIP-Big-5, Goldberg, 2006), which measures the Big-5 traits of extraversion, neuroticism, openness, conscientiousness and agreeableness using ten questions per trait. Each statement was to be rated on a scale from 1 (extremely inaccurate) to 7 (extremely accurate). The IPIP has indicated good convergent and discriminant validity (Lim \& Ployhart, 2006; Socha, Cooper, \& McCord, 2010). The current study found acceptable reliability for all subscales (extraversion: $\alpha=89$; agreeableness: $\alpha=82$; neuroticism: $\alpha=87$; openness: $\alpha=77$; and conscientiousness: $\alpha=82$ ).

3.3.4 Self-monitoring. A revised version of Snyder's Self-Monitoring Scale assessed self-monitoring (Lennox \& Wolfe, 1984). This 13-item questionnaire asks participants to rate on a 6 -point scale $(0=$ certainly always false, $5=$ certainly always true $)$ the extent to which each statement is true of them. The two sub-scales of this measure are: "ability to modify SP" and "sensitivity of expressive behaviour in others", although the current study employed only the former of these. This measure has been found to be valid and reliable (ability to modify: $\alpha$ $=.77$; total sale: $\alpha=.75$; Lennox \& Wolfe, 1984), further supported by the current study's reliability analysis of $\alpha=.77$ for the modifying SP sub-scale.

3.3.5 Emoticon usage. Emoticon usage was measured in two ways; self-reported usage and actual usage. To examine self-reported emoticon usage, a questionnaire was developed for the purposes of the current research. Initially, participants were asked to indicate on a "yes/no" basis whether they used emoticons in text messages, emails, and Facebook. Further to this, 
participants rated on a 5 -point scale $(1=$ never, $5=$ almost always $)$ the extent to which they used emoticons when communicating in these different online contexts. These scores were used in the subsequent analysis as a measure of self-reported usage.

To obtain objective data on actual emoticon usage, two coders were recruited to score the number and type of emoticons used in the Facebook profile and 'chat' profiles. Both coders worked independently and achieved $100 \%$ consensus between the coders. From the coding procedure, three categories of emoticons were identified. These were "happy", "sad" and "other".

\section{Results}

Frequency analysis of the yes/no responses was undertaken to gain insight on the proportion of the sample who reported using emoticons in each of the three contexts. This revealed that the majority of participants report using emoticons in text messages (89.1\%), with less using this communicative tool in Facebook (76.1\%) or email contexts (15.2\%). In order of magnitude the overall mean ratings of perceptions of privacy of the three contexts were as follows; email $=3.78(S D=1.10)$, text messages $=3.86(S D=1.10)$ and Facebook $=2.91(S D$ =1.26). Further descriptive analysis was undertaken on all study variables (see Table 1).

To examine the impact of context on self-reported differences in amount of emoticon usage, a one-way repeated measures ANOVA was performed with context as the independent variable and self-reported emoticon usage as the dependent variable. A significant effect of context was found, $F(2,160)=125.16, p<.001, \eta p^{2}=.96$ whereby a greater use of emoticons was self-reported in Facebook $(M=4.32, S E=.09)$ than email $(M=3.98, S E=.13)$ and text based communication $(M=2.15, S E=.16)$. Similarly, a greater use of emoticons were reported 
in email $(M=3.98, S E=.13)$ than text $(M=2.15, S E=.16)$, all $p$ 's $<.001$. Thus, emoticon usage was reported as greatest on Facebook, followed by email then text messages.

\subsection{Psychological Factors and Self-Reported Emoticon usage}

To determine the relationship between psychological factors and self-reported emoticon use, a series of zero-order Pearson correlations were conducted (Table 1). This revealed only one significant relationship: agreeableness was positively related with selfreported emoticon usage in the context of Facebook $(r=.27, p<05)$, but not in text messages $(r=.11, p=.31)$ or emails $(r=-.06, p=.61)$. Self-esteem and the sub-scales of social anxiety and self-monitoring, however, did not indicate any significant relationships with self-reported emoticon usage in any of the online contexts.

[Insert Table 1 about here]

When considering the psychological factors and general SP strategies, however, more relationships were observed. Specifically, agreeableness $(r=.35, p<.001)$ and extraversion $(r$ $=.49, p<.001)$ were positively related to modifying SP. Interestingly, modifying SP was negatively related to social anxiety in social interactions $(r=-.33, p<.001)$ and social avoidance in social interactions $(r=-.23, p<.05)$. Finally, self-esteem was positively related to self-reported modifying SP $(r=35, p<.05)$.

\subsection{Psychological Factors and Actual Emoticon Usage}

Examining actual emoticon usage as determined by coding of Facebook/chat profiles enabled a more fine-grained analysis of the relationships. Openness to experience was specifically positively correlated with usage of "other" emoticons (e.g., "wink" face; $r=.53, p$ 
$<.05$ ), and conscientiousness was marginally negatively related to usage of "sad" emoticons $(r=-.44, p=.06)$. Finally, modifying SP was negatively related to usage of "sad" emoticons $(r=-.53, p<.05)$

\section{Discussion}

Study 1 aimed to provide an account of the psychological correlates of emoticon usage across online contexts to assess: i) key psychological factors associated with self-reported and actual usage of emoticons; and ii) potential differential usage as a product of these contextual variations. Findings identified differences in the extent to which participants reported they used emoticons in the three contexts of text messages, Facebook and email. When viewed alongside the findings for actual emoticon usage our data reveal important correlates of online behaviour. Namely, agreeableness positively correlated with self-reported emoticon usage on Facebook, but not in the other contexts. This is justifiable given that Facebook, like most SNSs, largely represents a high level of social involvement with others, therefore offering more opportunities to modify emotional behaviours and interactions. These findings highlight the importance of a context-specific approach when examining the correlates of online behaviour, such as emoticons, particularly given their usage is largely determined by the context of their occurrence (Vandergriff, 2013).

In relation to the behavioural data gained through Facebook we were able to explore more fully the contextual influences on emoticon usage in terms of actual usage versus selfreported emoticon usage. Differences in the correlates of emoticon usage as a function of online context were found. Specifically, although agreeableness was found to be related to selfreported emoticon usage on Facebook, this was not corroborated within the objective emoticon data. Instead the latter revealed that openness and conscientiousness were crucial traits. One reason for these discrepancies may be that type of emoticon were not specified within the self- 
report data whereas they were in the objective data. Additionally, these discrepancies may be solely attributable to methodological issues common in self-report research. Nevertheless, these findings highlight the utility of a multi-methodological approach to understanding human behaviour.

The finding that openness was positively related to a variety of emoticons is, to some extent, supported by research that has found this trait to be related to a range of linguistic cues and expressive language (e.g., Mairesse, Walker, Mehl, \& Moore, 2007; Mehl, Gosling, \& Pennebaker, 2006). Indeed, facets of openness have been found to correlate with words relating to insight along with a limited use of the past tense (Mehl et al., 2006). The extent to which emoticons represent these previously observed cues is debatable, however, our findings suggest diversity in emotional expression via emoticons in CMC may be a useful cue to accurately judging individuals' levels of openness.

Although there were a number of non-significant correlations between the other psychological factors and emoticon usage, some of the relations with general self-reported SP were noteworthy. That is, agreeableness and extraversion were particularly key in their positive relationships with modifying SP behaviours. These two traits are interpersonal traits and arguably socially desirable traits (Riggio \& Friedman, 1986), thus, the relations with SP make intuitive sense and speak to the importance of trait-specific differences in SP.

Additionally, facets of social anxiety and avoidance were generally negatively associated with SP modification efforts whereby those higher in social anxiety, demonstrated lower self-monitoring behaviours. These findings are intriguing and, we believe, warrant further investigation. Our data suggests that those who were anxious found it difficult to monitor their behaviour. This possibility has also been noted by Funder (1995) who, in reference to motivational styles of information processing, comments that defensiveness can distort processing of information cues (John \& Robins, 1994). Understanding facets of social 
anxiety and its role in online interactional behaviour is therefore a key concern for future research.

Finally, self-esteem was positively related to general SP modification, which supports previous research (Mhedizadeh, 2010). This finding is opposite to that of social anxiety reported above and bolsters the tentative explanation that anxiety and low self-esteem may negatively impact on SP behaviour and warrants further research attention. Clearly these factors have a role in general self-monitoring behaviours but perhaps it could be argued here that emoticon usage is not a fundamental source of SP behaviour, or that efforts of SP are not the primary motive in their usage. This may account for why there were not more associations between the psychological factors of interest with usage data.

In summation, we have been able to identify some initial factors (psychological and contextual) relevant in individuals' emoticon usage, as a potential indicator of SP efforts. However, to examine the practical utility of these findings and develop our theoretical understanding of how personality is revealed, and judged, through behaviour, it is imperative to explore the impact of these behaviours on the accuracy of first impressions. This formed the basis for Study 2, in which we used the Facebook profiles and chat interaction data as a stimuli through which naïve observers made personality judgements of these targets.

\section{Study 2: Personality Judgements}

The accuracy of personality judgements based on first impressions has been examined in many contexts, including face-to-face interaction (Funder, Kolar, \& Blackman, 1995; Letzring, Wells, \& Funder, 2006) and telephone conversations (Wall et al., 2013). Of greater interest to the current study is that people are also able to form accurate first impressions within online contexts (e.g., synchronous and asynchronous email, Gill, Oberlander, \& Austin, 2006; Kruger, Epley, Parker, \& Ng, 2005; Hancock \& Dunham, 2001). While personality can be judged 
accurately, individuals often monitor their behaviour both offline and online to present themselves in the best light (Leary, 1995; Kramer \& Winter, 2008, respectively). Although much research has examined SP in face-to-face interactions, less is known about the types of online behaviour that may be prone to SP effects and the subsequent impact that this has on the accuracy of personality impressions.

Recent evidence highlights that use of positive emoticons in text messages can reduce negative perceptions of the user (Kingsbury, 2014), and that emoticon users are judged to be more out-going than non-users (Darbyshire, Kirk, Wall, \& Kaye, 2016; Fullwood \& Martino, 2007). However, the 'accuracy' of perceptions based on emoticon usage has not been examined. More specifically, how personality, SP, online emoticon use and impression accuracy across online contexts inter-relate. This represents a major objective of the present study. Study 1 revealed some initial insight into the role of particular personality traits on emoticon usage on the context of Facebook, specifically: 1) emoticon use differs depending upon the specific platform; and 2) personality is only related to emoticon use on Facebook. Given these differences, it is interesting to examine how emoticon use can influence personality judgements across a range of contexts. Study 2 focused on two online contexts: Facebook and online 'chat' and considered how emoticon usage may vary across these contexts. Moreover, in line with the growing research on the relationship between online 'cues' and impressions (e.g., Fullwood \& Martino, 2007; Stopfer, Egloff, Nestler \& Back, 2014; Walther et al., 2008) our methodology permits an investigation into the role of different emoticons in online impression accuracy.

The majority of research examining the link between behaviour and personality in offline settings has focused largely on the trait of extraversion (e.g., Scherer, 1978, 1986) or emotional states and non-verbal behaviour (Ekman, 1985; Ekman, Friesen, \& Ellsworth, 1972). Berry and Hansen's (2000) report that low agreeableness was related to 'negative facial expressions' 
suggests there may be a link between personality and online emoticon usage. By definition, personality encompasses an individual's thoughts and feelings; thus, cues indicating emotion (i.e., emoticons) should be linked to personality. In support, Ekman (1992; see also Izzard, 1977) states that emotions are communicated to others in distinct facial expressions, which is likely part of the expressive style of personality. Emotional expressions play a role in fostering the nature of interactions with others (and vice versa) (Keltner, 1996) and the online context in this respect is largely equivalent. Therefore, the extent to which emotional expression is formulated and facilitated as a product of the interactivity of the online context is an interesting area of research enquiry.

More recently, researchers have begun to examine the accuracy of judgements formed in a range of online contexts such as online blogs (Biel, Aran, \& Gatica-Perez, 2011) email (Back et al., 2008) and Facebook (Back et al., 2010) but few studies have compared findings across contexts or provided compelling evidence of the specific underpinnings of judgement accuracy (see Walther et al., 2008). Such findings are useful in developing an understanding of how personality is revealed through online behaviour, and highlight differences between online and offline behaviours (see DeAndrea \& Walther, 2007).

Moreover, another group of studies have explored the links between online cues and judgements formed with an online context (e.g., Walther et al., 2008), and other studies have examined the impact of targets' personality on the type of judgements formed (Colvin, 1993; see also Funder, 1995). However, to the best of our knowledge, no study has examined these critical factors together in one study. More specifically, the major objective of Study 2 is to examine how accurately individuals can be judged on the basis of two online contexts: Facebook and online 'chat'. Finally, a novel objective of the study is to explore the relation between objectively coded and self-reported emoticon cue usage and judgement accuracy. Consequently, this study examines the following research questions: 
1. How 'accurate' are observers when rating personality on the basis of viewing online behaviour?

2. How does actual emoticon usage relate to the judgement of another's personality?

\section{Method}

\subsection{Participants}

Using the Facebook profiles and 'chat' data obtained from Study $1(n=54)$, a group of naive observers $(N=7)$ rated their impressions of the target participants. Initially 10 observers were recruited, however three did not complete all targets' profiles, therefore resulting in a total sample of seven who provided a full set of responses. Of these seven, five were female and two were male and all Psychology undergraduates.

\subsection{Design and Procedure}

A correlational design was used to investigate the role of context and emoticon cue usage on first impression accuracy for the Big Five personality traits. Observers independently rated their impressions of all 54 target participants based solely on viewing their Facebook and chat profiles, resulting in a total of 378 judgements. Given the length of time involved in rating all targets, this was conducted over five 2-hour rating sessions across a period of five weeks (see Gosling et al. 2007 for similar procedure). Observers reported that they were not acquainted with any of the target participants, therefore removing this potential confound.

\subsection{Measures}

7.3.1 Personality Judgements. Observers' impressions of the participants' personality was assessed using a modified version of the 50-item IPIP used in Study 1. Specifically, each item was prefaced with "I think the person whose Facebook profile/chat profile I have viewed 
is...' to ensure personality assessment related to the intended target. Reliability analyses was conducted for each trait per observer and aggregated across all observers per trait, revealing highly acceptable reliability. For simplicity, we report the aggregate scores for each trait here, specifically extraversion $(\alpha=.80)$, agreeableness $(\alpha=.86)$, conscientiousness $(\alpha=.82)$, neuroticism $(\alpha=.76)$, and openness $(\alpha=.73)$.

\subsection{Measuring 'Accuracy'}

Accuracy is a fraught term (Funder, 2012) and has been labelled self-other agreement (see Funder, 1995, 1999). In essence, here it refers to the validity of a judgment made about a person in terms of whether it converges with the target's personality. In other words, do observers see a target person the same way as that target sees themselves? Accuracy was measured using two methods. First overall observer accuracy was computed by correlating aggregated observer ratings with the participants self-report, thus reflecting the accuracy of the group of observers. Next, single-observer accuracy was determined by the mean pairwise correlation between each observer and the target participants' self-report, therefore reflecting the mean accuracy of a single observer (see Gosling, Gaddis, \& Vasire, 2007 for similar analytical procedure). Significant correlations represent 'accurate' judgements with $r$-values closer to 1 being deemed as more accurate.

\section{Results}

A number of correlational analyses were undertaken to assess the extent of convergence across all observers (consensus) and agreement (accuracy) between observers and the targets' self-reported personality scores from Study 1 (see Table 2). Specifically, intra-class correlations, ICC's $(2,1)$ (Shrout \& Fleiss, 1979) were performed across the seven observers' 
trait scores to gain a consensus score and this revealed significant agreement for all traits, with the exception of conscientiousness (see Table 2).

To explore personality trait accuracy, a number of analyses were conducted. First, targets' self-reported traits were correlated with each observers' rating of these targets for an accuracy score per observer per trait; thus, each observer had as many accuracy scores as targets. From this, a mean single observer accuracy score (i.e., across traits) was obtained, resulting in 54 correlations (one per target). Additionally, correlation coefficients were obtained between targets' self-reports and the aggregate observers' rating per trait. These revealed good levels of accuracy, in particular for extraversion $(r=.74, p<001)$, and openness $(r=44, p<05)$.

\section{[Table 2 about here]}

A final analysis assessed the relationship between personality judgements and behavioural usage of emoticons. Here positive correlations were found between targets' use of “happy” emoticons and observers' assessments of agreeableness $(r=.74, p<.01)$, conscientiousness $(r=.63, p<.05)$, and openness $(r=.63, p<.05)$.

\section{Discussion}

Study 2 had two major aims: to examine the accuracy of first impressions formed after viewing an individuals' online behaviour and to explore the role of a specific form of online behaviour - emoticon usage - in shaping judgments across traits. Findings revealed high judgement accuracy for extraversion and openness, and positive relationships between usage of positive "happy" emoticons with judgements on agreeableness, openness and conscientiousness. 
The findings concerning accuracy for extraversion are largely consistent with a wealth of research regarding online and offline contexts, supporting that this trait tends to be accurately judged (Vazire \& Gosling, 2004; see Funder, 1999). The present finding therefore adds to the growing literature concerning extraversion as an 'easy' to judge trait in terms of its accessible behavioural manifestations, even within online contexts (Mairesse, Walker, Mehl, \& Moore, 2007). The finding that openness was accurately rated online converges with recent studies examining Facebook profiles (Gosling et al., 2007) and websites (Vazire \& Gosling, 2004). This recent research highlighted that in an online context, accuracy for this trait is high, thus standing in stark contrast to offline studies where openness is difficult to judge. Interestingly this particular pattern of findings corroborates recent research into differential trait perceptions that vary in terms of the public-private context being examined. Specifically, Holleran and Mehl's (2007) study of judgements based on a stream of consciousness writing, and thus a more private context of SP, found that these two traits (extraversion and openness) were rated more accurately than the remaining ones.

Furthermore, recent researchers have argued that these more nuanced context-trait relations can enhance our theoretical understanding of personality and perception (Vandergriff, 2013). Digman (1997) proposed that two higher order meta-traits underlie the Big Five. These meta-traits have been labelled as Stability (comprising agreeableness, conscientiousness, and neuroticism), which reflects internal motivational and emotion components of an individual, and Plasticity (comprising extraversion and openness) which refers to external processes including exploration of the social world (DeYoung, 2006). Our findings that the "plasticity" traits were judged accurately converges with Hollerahn and Mehl's findings and suggests an interesting lens through which to interpret perception processes in online contexts. Given that the trait of openness is typically difficult to judge offline, our findings suggest that online 
contexts permit the expression of openness to a greater extent than offline contexts, and that observers can detect these expressions.

Consensus analysis revealed good agreement across observers for all traits, with the exception of conscientiousness. At first glance this findings is surprising as conscientiousness is often highlighted as one of the most accurately judged traits along with extraversion (Albright, Kenny, \& Malloy, 1988). However, this pattern tends to be observed primarily in offline contexts. As noted by a number of researchers (e.g., Vandergriff, 2013; Wall et al., 2016) the ease with which a trait is judged interacts with the informational context through which it is revealed. This is supported in our data as openness was accurately judged whereas studies examining offline interactions report that this trait is difficult to judge (Wall et al., 2013). Finally, the observed relationships between "happy" emoticon usage and judgements on the traits of agreeableness, conscientiousness and openness are noteworthy. That is, this suggests online positive emotional expression is positively related to others' perceptions of traits that are typically considered to be socially desirable in nature.

\section{General Discussion}

The current research offers a number of new findings to the literature, providing theoretical implications for our understanding of how we behave online and how others use this behaviour to form personality judgements. First, we demonstrated that agreeableness was related to context-specific emoticon usage; specifically, agreeableness was related to self-reported usage in Facebook but not the other contexts. This supports person-context interactions typically revealed offline (Jacobs, Van Os, Derom, Thiery, Delespaul, \& Wichers, 2011) and highlights the need to move beyond conceptions of the Internet as a unidimensional environment. Our data suggest that what we do and when we choose to do this is nuanced and highlights the need for context specific explorations of these issues. 
Our findings also offer a practical implication in terms of the traits that were more accurately judged in certain contexts, which may be useful for practitioners conducting remote personality assessments and organisations in their recruitment practises (see Chapman \& Rowe, 2001). Specifically, we demonstrated that judgement accuracy was highest for the more "publicly oriented" traits of extraversion and openness, which develops the evidence-base surrounding meta-traits (Digman, 1997). This pattern of differential accuracy across traits complements and extends theoretical models of judgement accuracy (see Funder, 1995, 1999). That is, differences in accuracy by trait type highlights that even when faced with limited information cues we are able to usefully distinguish between types of online cues and use these to form accurate judgements, at least for the traits of extroversion and openness.

Our data highlighted an important methodological implication whereby a focus on comparing self-reported behaviour and actual behaviour revealed differences in the context of Facebook (see also Vohs et al., 2007). Although further research is needed to investigate the mechanisms underlying these differences our findings suggest that in certain contexts what we say we do and what we do may differ.

When considering alternative explanations it is important to consider some potential limitations. The focus on only one type of online behaviour - that of emoticon usage - limits the breadth of our conclusions in terms of the cues available which observers may have used to form impressions. Importantly, given the exploratory nature of this research we do not directly link cue use with accuracy in judgements, rather, our data reveal interesting relationships between emoticon usage and personality and warrant further research attention More specifically, our study provides an important first step in terms of the psychological correlates of emoticon usage and how perceptions of usage differ from actual usage. Indeed, a useful avenue for future investigation would be to extend this line of reasoning and 
qualitatively explore the motivations underlying the different types of emoticon use and the purpose they serve for the user (Kaye et al., in press).

A further limitation is that although we identified differential emoticon usage between online contexts (Study 1), a more detailed understanding of how and why these contexts resulted in these differences remains unanswered. It would be useful for future research to provide additional insight into what contextual factors determine the extent of emoticon usage. Indeed, previous research identifies work-related emails as one context in which emoticon usage is perceived to be more unprofessional yet less negative in nature than those without emoticons (Gacey \& Richard, 2013). We believe that our analyses are appropriate for the nature of our research questions and encourage further research to adopt approaches that utilise these behavioural forms of data gathering within specific online contexts.

Taken together, our findings for accuracy and the relations between cue use and first impressions have important social implications. Namely, contemporary systems increasingly rely on online context for initiating and maintaining communications (e.g., online dating and online job recruitment). In these online contexts, first impressions are paramount. Therefore, understanding the behaviours which enable users to present themselves better for enabling such impressions is an area of practical significance. 
Declaration of Conflicting Interest.

The authors declare no potential conflicts of interest with respect to the research, authorship, and/or publication of this article.

Funding.

No funding was sought for this research 
EMOTICON USAGE AND PERSONALITY JUDGEMENTS

\section{References}

Albright, L., Kenny, D. A., \& Malloy, T. E. (1988). Consensus in personality judgements at zero acquaintance. Journal of Personality and Social Psychology, 55 (3), 387-395. doi: $10.1037 / 0022-3514.55 .3 .387$

Alfi, M., \& Talbot, P. (2013). Health-related effects reported by electronic cigarette users in online forums. Journal of medical Internet research, 15(4), e59.

Amichai-Hamburger, Y., \& Vinitzky, G. (2010). Social network use and personality. Computers in Human Behavior, 26, 1289-1295. doi: 10.1016/j.chb.2010.03.018

Argyle, M., Martin, M., \& Crossland, J. (1989). Happiness as a Function of Personality and Social Encounters. In J. P. Forgas, \& J. M. Innes (Eds.), Recent Advances in Social Psychology: An International Perspective (pp. 189-203). Amsterdam: North Holland, Elsevier Science. 
Ashrafioun, L., McCarthy, A., \& Rosenberg, H. (2012). Assessing the impact of cue exposure on craving to gamble in university students. Journal of Gambling Studies, 28(3), 363 375.

Attrill, A. (2012). Sharing online parts of me: Selective categorical self-disclosure across internet arenas. International Journal of Internet Science, 7 (1), 55-77.

Back, M. D., Schmukle, S. C., \& Eglogff, B. (2008). How extraverted is honey.bunny77@homail.de? Inferring personality from email addresses. Journal of Research in Personality, 42 (4), 1116-1122

Back, M. D., Stopfer, J. M., Vazire, S., Gaddis, S., Schmukle, S. C., Egloff, B., \& Gosling, S. D. (2010). Facebook profiles reflect actual personality, not self-idealization. Psychological Science, 21 (3), 372-374. doi: 10.1177/0956797609360756

Baumeister, R. F. (1982). Self-esteem, SP and future interactions: A dilemma of reputation. Journal of Personality, 50 (1), 29-45

Baumeister, R. F., Vohs, K. D., \& Funder, D. C. (2007). Psychology as the science of selfreports and finger movements: Whatever happened to actual behavior? Perspectives on Psychological Science, 2(4), 396-403.

Bernieri, F. J., Gillis, J. S., Davis, J. M., \& Grahe, J. E. (1996). Dyad rapport and the accuracy of its judgement across situations: A lens model analysis. Journal of Personality and Social Psychology, 71 (1), 110-129

Berry, D. S., \& Hansen, J. S. (2000). Personality, nonverbal behavior, and interaction quality in female dyads. Personality and Social Psychology Bulletin, 26(3), 278-292.

Briley, D. A., Domiteaux, M., \& Tucker-Drob, E. M. (2014). Achievement-relevant personality: Relations with the Big Five and validation of an efficient instrument. Learning and Individual Differences, 32, 26-39. 
Burke, P. J. (2004). Identities and social structure: The 2003 Cooley-Mead award address. Social Psychology Quarterly, 67(1), 5-15.

Bullingham, L., \& Vasconcelos, A. C. (2013). The presentation of self in the online world: Goffman and the study of online identities. Journal of Information Science, 39 (1), 101-112. doi: $10.1177 / 0165551512470051$

Caplan, S. E. (2007). Relations among loneliness, social anxiety, and problematic Internet use. CyberPsychology \& Behavior, 10, 234-242.

Carney, D. R., Colvin, C. R., \& Hall, J. A. (2007). A thin slice perspective on the accuracy of first impressions. Journal of Research in Personality, 41(5), 1054-1072.

Carpenter, C. J. (2012). Narcissism on Facebook: Self-promotional and anti-social behaviour. Personality and Individual Differences, 52, 482-486. doi: 10.1016/j.paid.2011.11.011

Chapman, D. S., \& Rowe, P. M. (2001). The impact of videoconference technology, interview structure, and interviewer gender on interviewer evaluations in the employment interview: A field experiment. Journal of Occupational and Organizational Psychology, 74(3), 279-298.

Colvin, C. R. (1993). Childhood Antecedents of Young-Adult Judgability. Journal of Personality, 61(4), 611-635.

Coppersmith, S. (1967). The antecedents of self-esteem. San Francisco: Freeman

Darbyshire, D. E., Kirk, C., Wall, H. J., \& Kaye, L. K. (2016). Don’t Judge a (Face)Book by its Cover: Exploring Judgement Accuracy of Others' Personality on Facebook. Computers in Human Behavior, 58, 380-387. doi:10.1016/j.chb.2016.01.021

DeAndrea, D. C., \& Walther, J. B. (2011). Attributions for inconsistencies between online and offline self-presentations. Communication Research, 38 (6), 805-825. doi: $10.1177 / 0093650210385340$ 
Derks, D., Arjan E.R., Grumbkow, von J., (2007). Emoticons and social interaction on the Internet: the importance of social context. Computers in Human Behavior, 23 (1), $842-849$

Derks, D., Bos, A. E. R., von Grumbkow, J. (2008). Emoticons in computer-mediated communication: Social motives and social contexts. Cyberpsychology \& Behaviour, 11 (1), 99-101

DeYoung, C. G. (2006). Higher order factors of the big five in a multi-informant sample. Journal of Personality and Social Psychology, 91, 1138-1151

Ebeling-Witte, S., Frank, M. L., \& Lester, D. (2007). Shyness, Internet use, and personality. CyberPsychology \& Behavior, 10(5), 713-716.

Ekman, P. (1985). Telling lies. New York: W. W. Norton.

Ekman, P. (1992). An argument for basic emotions. Cognition \& emotion, 6(3-4), 169-200.

Ekman, P., Friesen, W. V., \& Ellsworth, P. (1972). Emotion in the human face: Guidelines for research and a review of findings. New York. Permagon.

Eftekhar, A., Fullwood, C., \& Morris, N. (2014). Capturing personality from Facebook photos and photo-related activities: How much exposure do you need? Computers in Human Behavior, 37, 162-170. doi: 10.1016/j.chb.2014.04.048

Festinger, L. (1954). A theory of social comparison processes. Human Relations, 7 (2), 117 140

Fullwood, C. (2015). The role of personality in online self-presentation. In A. Attrill (Ed.), Cyberpsychology (pp. 9-28). Oxford: Oxford University Press

Fullwood, C. \& Martino, O.I. (2007). Emoticons and Impression Formation. Applied Semiotics, 19, 4-14.

Fullwood, C., Orchard, L., \& Floyd, S. (2013). Emoticon convergence in Internet chat rooms. Social Semiotics, 23(5), 648-662 
Fullwood, C., Quinn, S., Chen-Wilson, J., Chadwick. D., \& Reynolds, K. (2015). Put on a smiley face: Textspeak and personality perceptions. Cyberpsychology, Behavior and Social Networking. $18(3), 147-151$

Funder, D. C. (1995). On the accuracy of personality judgment: a realistic approach. Psychological Review, 102(4), 652.

Funder, D. C. (Ed.). (1999). Personality judgment: A realistic approach to person perception. London: Academic Press.

Funder, D. C., \& Colvin, C. R. (1991). Explorations in behavioral consistency: properties of persons, situations, and behaviors. Journal of Personality and Social Psychology, 60 (5), 773.

Funder, D. C., Kolar, D. C., \& Blackman, M. C. (1995). Agreement among observers of personality: interpersonal relations, similarity, and acquaintanceship. Journal of Personality and Social Psychology, 69(4), 656.

Gacey, H. J., \& Richard, E. M. (2013). Influence of emoticons on perceived negative affect and professionalism in work-related email. Proceedings of the Academy of Management, 14646

Ganster, T., Eimler, S. C., \& Kramer, N. C. (2012). Same same but different!? The differential influence of smilies and emoticons on person perception. Cyberpsychology, Behaviour, and Social Networking, 15(4), 226-230

Gill, A. J., Oberlander, J., \& Austin, E. (2006). Rating email personality at zero acquaintance. Personality and Individual Differences, 40 (3), 497-507

Goffman, E. (1990). The presentation of self in everyday life. London: Penguin

Goldberg, L. R., Johnson, J. A., Eber, H. W., Hogan, R., Ashton, M. C., Cloninger, C. R., \& Gough, H. G. (2006). The international personality item pool and the future of publicdomain personality measures. Journal of Research in Personality, 40(1), 84-96. 
Gosling, S.D., Gaddis, S., \& Vazire, S. (2007, March). Personality impressions based on Facebook profiles. Paper presented at the International Conference on Weblogs and Social Media. Boulder, Colorado

Green, M. C. (2007). Trust and social interaction on the Internet. In A. Joinson, K. McKenna, T. Postmes \& U. Reips (Eds.), The Oxford Handbook of Internet Psychology (pp. 4351). Oxford: Oxford University Press

Hancock, J. T., \& Dunham, P. J. (2001). Impression formation in computer-mediated communication revisited an analysis of the breadth and intensity of impressions. Communication Research, 28(3), 325-347.

Hancock, J. T., \& Toma, C. L. (2009). Putting your best face forward: The accuracy of online dating photographs. Journal of Communication, 59, 367-386

Heine, S. J., Buchtel, E. E., \& Norenzayan, A. (2008). What do cross-national comparisons of personality traits tell us?: The case of conscientiousness. Psychological Science, 19 (4), $309-313$

Holleran, S. E., \& Mehl, M. R. (2008). Let me read your mind: Personality judgements based on a person's natural stream of thought. Journal of Research in Personality, 42, 747754

Jacobs, N., Van Os, J., Derom, C., Thiery, E., Delespaul, P., \& Wichers, M. (2011). Neuroticism explained? From a non-informative vulnerability marker to informative person-context interactions in the realm of daily life. British Journal of Clinical Psychology, 50(1), 19-32.

John, O. P., \& Robins, R. W. (1994a). Accuracy and bias in self-perception: Individual differences in self-enhancement and narcissism. Journal of Personality and Social Psychology, 66, 206-219. 
Kaye, L. K., Wall, H. J., \& Malone, S. A. (in press). "Turn that frown upside-down": A contextual account of emoticon usage on different virtual contexts. Computers in Human Behavior. doi: 10.1016/j.chb.2016.02.088

Keltner, D. (1996). Evidence for the distinctness of embarrassment, shame, and guilt: A study of recalled antecedents and facial expressions of emotion. Cognition \& Emotion, 10(2), $155-172$.

Kingsbury, M. (2014).RU Mad@me: Social anxiety and interpretation bias in computermediated contexts. Unpublished doctoral dissertation (Carleton University, Ottawa Canada).

Krämer, N. C., \& Winter, S. (2008). Impression management 2.0: The relationship of self esteem, extraversion, self-efficacy, and self-presentation within social networking sites. Journal of Media Psychology, 20(3), 106-116.

Kruger, J., Epley, N., Parker, J., \& Ng, Z. (2005). Egocentrism over email: Can we communicate as well as we think? Journal of Personality and Social Psychology, 89 (6), 925-936

Lea, M., \& Spears, R. (1992). Paralanguage and social perception in computermediatedcommunication. Journal of Organisational Computing, 2, 321-342

Leary, M. R. (1995). Self-presentation: Impression management and interpersonal behavior. Brown \& Benchmark Publishers.

Leary, M. R., \& Allen, A. B. (2011). Personality and persona: Personality processes in selfpresentation. Journal of Personality, 79 (6), 889-916

Leary, M. R., \& Baumeister, R. F. (2000). The nature and function of self-esteem: Sociometer theory. In M. P. Zanna (Ed.). Advances in Experimental Social Psychology (Vol. 32, pp. 1-62). San Diego: Academic Press. 
Leary, M. R., \& Kowalski, R. M. (1990). Impression management: A literature review and two component models. Psychological Bulletin, 107 (1), 34-47

Lee, S., Quigley, B. M., Nesler, M. S., Corbett, A. B., \& Tedeschi, J. T. (1999). Development of a self-presentation tactics scale. Personality and Individual Differences, 26, 701-722

Lennox, R. D., \& Wolfe, R. N. (1984). Revision of the self-monitoring scale. Journal of Personality and Social Psychology, 46 (6), 1349-1364

Letzring, T. D., Wells, S. M., \& Funder, D. C. (2006). Information quantity and quality affect the realistic accuracy of personality judgment. Journal of Personality and Social Psychology, 91(1), 111.

Liebowitz, M. R. (1987). Social phobia. Modern Problems in Pharmacopsychiatry, 22, 141 173.

Lim, B., Ployhart, R. E. (2006). Assessing the convergent and discriminant validity of Goldberg's International Personality Item Pool: A multitrait-multimethod examination. Organizational Research Methods, 9, 29-54. doi: $10.1177 / 1094428105283193$

Mairesse, F., Walker, M. A., Mehl, M. R., \& Moore, R. K. (2007). Using linguistic cues for the automatic recognition of personality in conversation and text. Journal of Artificial Intelligence Research, 30, 457-500

Marriot, T. C., \& Buchanan, T. (2014). The true self online: Personality correlates of preference for self-expression online, and observer ratings of personality online and offline. Computers in Human Behavior, 32, 171-177. doi:

10.1016/j.chb.2013.11.014

Mehdizadeh, S. (2010). Self-presentation 2.0: Narcissism and Self-Esteem on Facebook,Cyberpsychology, Behaviour \& Social Networking, 13, 4, 357-364 doi:10.1089/cyber.2009.0257 
Mehl, M. R., Gosling, S. D., \& Pennebaker, J. W. (2006). Personality in its natural habitat: Manifestations and implicit folk theories of personality in daily life. Journal of Personality and Social Psychology, 90, 862-877

Nie, N. H. (2001). Sociability, interpersonal relations and the Internet: Reconciling conflicting findings. American Behavioral Scientist, 45 (3), 420-435

Pierce, T. (2009). Social anxiety and technology face-to-face communication versus technological communication among teens. Computers in Human Behavior, 25, $1367-1372$.

Qiu, L., Lin, H., Ramsay, J., \& Yang, F. (2012). You are what you tweet: Personality expression and perception on Twitter. Journal of Research in Personality, 46 (6), 710-718

Rentfrow, P. J., \& Gosling, S. D. (2006). Message in a ballad: The role of music preferences in interpersonal perception. Psychological Science, 17, 236-242

Riggio, R. E., \& Friedman, H. S. (1986). Impression formation: The role of expressive behavior. Journal of Personality and Social Psychology, 50 (2), 421-427. doi: $10.1037 / 0022-3514.50 .2 .421$

Rosenberg, M. (1965). Society and the Adolescent Self-Image. Princeton, NJ: Princeton University Press.

Rosenberg, J., \& Egbert, N. (2011). Traits and concerns for secondary goals as predictors of SPs tactics on Facebook. Journal of Computer-mediated Communication, 17, 1-18. doi: 10.1111/j.1083-6101.2011.01560.x

Rosenfield, M. J. (2010). Meeting online: The rise of the Internet as a social intermediary. Paper presented at the American Sociological Association Annual Meeting. Retrieved June 3, 2015 from www.allacademic.com/meta/p409508 index.html

Scherer, K. R. (1978). Personality inference from voice quality: The loud voice of extroversion. European Journal of Social Psychology, 8(4), 467-487. 
Scherer, K. R. (1986). Vocal affect expression: a review and a model for future research. Psychological Bulletin, 99(2), 143.

Schlenker, B. R. (2003). Self-presentation. In M. R. Leary \& J. P. Tangney (Eds.), Handbook of self and identity (pp. 492-518). New York: Guilford

Schlenker, B. R., \& Leary, M. R. (1982). Social anxiety and self-presentation: A conceptualization and model. Psychological Bulletin, 92(3), 641-669

Shalon, J. G., Israelo, H., Markovitzky, O., \& Lipsitz, J. D. (2015). Social anxiety and physiological arousal during computer mediated versus face to face communication. Computers in Human Behavior, 44, 202-208

Shrout, P. E., \& Fleiss, J. L. (1979). Intraclass correlations: uses in assessing rater reliability. Psychological Bulletin, 86(2), 420.

Snyder, M. (1987). Public appearances/private realities: The psychology of self-monitoring. New York: Freeman.

Stopfer, J. M., Egloff, B., Nestler, S., \& Back, M. D. (2014). Personality expression and impression formation in online social networks: An integrative approach to understanding the processes of accuracy, impression management and meat-accuracy. European Journal of Personality, 28, 73-94

Suh, A. (2013). The influence of self-discrepancy between the virtual and real selves in virtual communities. Computers in Human Behavior, 29 (1), 246-256. doi: 10.1016/j.chb.2012.09.001

Thorne, A. (1987). The press of personality: A study of conversations between introverts and extraverts. Journal of Personality and Social Psychology, 53(4), 718.

Vandergriff, I. (2013). Emotive communication online: A contextual analysis of computermediated communication (CMC) cues. Journal of Pragmatics, 51, 1-12 
Vazire, S., \& Gosling, S. D. (2004). E-Perceptions: Personality impressions based on personal websites. Journal of Personality and Social Psychology, 87, 123- 132

Vazire, S., \& Mehl, M. R. (2008). Knowing me, knowing you: The accuracy and unique predictive validity of self-ratings and other-ratings of daily behavior. Journal of Personality and Social Psychology, 95, 1202-1216.

Wall, H. J., Taylor, P. J., Dixon, J., Conchie, S. M., \& Ellis, D. A. (2013). Rich contexts do not always enrich the accuracy of personality judgments. Journal of Experimental Social Psychology, 49(6), 1190-1195.

Walther, J. B. (1993). Impression development in computer-mediated interaction. Western Journal of Communication, 57 (4), 381-398. doi: 10.1080/10570319309374463

Walther, J. B. (1996). Computer-mediated communication: Impersonal. interpersonal and hyperpersonal interaction. Communication Research, 23 (1), 3-43

Walther, J. B., Van Der Heide, B., Kim, S. Y., Westerman, D., \& Tong, S. T. (2008). The role of friends' appearance and behavior on evaluations of individuals on Facebook: Are we known by the company we keep? Human Communication Research, 34(1), 28-49.

Yang, Y., Read, S. J., \& Miller, L. C. (2009). The concept of situations. Social and Personality Psychology Compass, 3(6), 1018-1037.

Yee, N., Harris, H., Jabon, M., \& Bailenson, J. N. (2011). The expression of personality in virtual worlds. Social Psychological and Personality Science, 2, 512.

Zhao, S., Grasmuck, S., \& Martin, J. (2008). Identity construction on Facebook: Digital empowerment in anchored relationships. Computers in Human Behavior, 24, 1816 1836. 